\title{
Erratum
}

Obstetrics \&

\section{Correction of Phrase: Medically unfit women with early- stage endometrial cancer treated with the levonorgestrel intrauterine system}

Manolis Nikolopoulos, MBBS, Michelle A.L. Godfrey, MBBS, MRCOG, Rekha Wuntakal, MBBS, MRCOG

In the published article, "Manolis Nikolopoulos, Michelle A.L. Godfrey, Rekha Wuntakal. Medically unfit women with earlystage endometrial cancer treated with the levonorgestrel intrauterine system. Obstet Gynecol Sci 2020;63(3):337-345. https://doi.org/10.5468/ogs.2020.63.3.337," we found an error in the above published article, and correct the error as below. The authors apologize for any inconvenience that it may have caused.

Old phrase on the page 339:

Change of the LNG-IUS was advised no later than thrice a year.

Corrected phrase:

Change of the LNG-IUS was advised every three years. 